Didáctica Geográfica nº 19, 2018,pp. 47-76

ISSN: 0210-492-X

D.L: M-3736-2014

\title{
LA ENCUESTA COMO HERRAMIENTA PARA CONOCER LAS IDEAS PREVIAS SOBRE PAISAJE DEL ALUMNADO DE ESO: UNA EXPERIENCIA PILOTO EN NAVARRA
}

María Casas Jericóí; Luis Erneta Altarriba²; Jordi Puig Baguer

Recibido: 23/03/2018

Aceptado: 20/09/2018

\section{RESUMEN:}

El Convenio Europeo del Paisaje (2000) reconoció la necesidad de desarrollar propuestas formativas y de sensibilización en materia de paisaje, encaminadas a lograr una ciudadanía concienciada y activa. Por este motivo, es adecuado conocer las ideas previas sobre paisaje de los ciudadanos, para, a partir de éstas, diseñar propuestas que respondan a las necesidades educativas reales. El presente artículo tiene por objeto mostrar una breve encuesta diseñada para lograr una primera aproximación a las ideas previas y preferencias paisajísticas del alumnado de Educación Secundaria Obligatoria de Navarra.

\section{Palabras clave:}

Encuesta, paisaje, ideas previas, preferencias paisajísticas, Educación Secundaria Obligatoria.

1 María Casas Jericó y Jordi Puig Baguer pertenecen a laUniversidad de Navarra, Facultad de Ciencias, Departamento de Biología Ambiental, Campus Universitario, 31008, Pamplona España. Tfno: 948425 600, Ext: 803320. Email: mcasas.1@alumni.unav.es; jpbaguer@unav.es

2 Universidad de Navarra, Facultad de Filosofía y Letras, Departamento de Historia, Historia del Arte y Geografía, Campus Universitario, 31011, Pamplona España. Tfno: 948425 600, Ext: 802310.Email: lerneta@alumni.unav.es 


\section{Abstract:}

The European Landscape Convention highlighted the importance of educating and raising awareness on landscapes in order to foster a participative citizenry. For this reason, finding out the citizens' prior knowledge of landscape allows designing proper educational proposals. This research presents a brief survey to study both the prior knowledge of landscape and the landscape preferences of Secondary Education students from Navarra (Spain).

\section{KEYWORDS:}

survey, landscape, prior knowledge, landscape preferences, Secondary Education.

\section{RÉSUMÉ:}

La Convention européenne du paysage (2000) a reconnu le besoin de développer des propositions formatives et de sensibilisation dans le domaine du paysage, dirigées vers le développement d'une population sensibilisée et active. C'est pour ça qu'on trouve adéquat connaître les idées préalables des citoyens sur le paysage pour, à partir de là, concevoir des propositions qui répondent aux nécessités éducatives réelles. Cet article a comme but montrer une brève enquête conçue pour réussir une première approximation aux idées préalables et préférences du paysage des élèves d'Enseignement Secondaire en Navarre.

\section{Mots clés:}

enquête, paysage, idées préalables, préférences du paysage, Enseignement Secondaire.

\section{INTRODUCCIÓN}

El Convenio Europeo del Paisaje (en adelante, CEP) lanzado por el Consejo de Europa en Florencia en el año 2000 supuso un punto de inflexión en materia de paisaje, que ha quedado reflejado no solo en el ámbito normativo, sino también en el académico. El CEP, además de proponer una definición para paisaje que trasciende el territorio e incorpora al sujeto perceptor, reconoce su dimensión patrimonial, su gran interés medioambiental, social y económico, y su papel en la calidad de vida y el bienestar del ser humano (Consejo de Europa, 2000). Asimismo, el CEP considera como paisaje no solo aquellos lugares de reconocida belleza excepcional, sino también los que pasan desapercibidos por resultar cotidianos para los ciudadanos e incluso los que están degradados.

El fin último del CEP es lograr una adecuada gestión, ordenación y protección de los paisajes europeos. Para ello, se requieren tanto políticas acertadas en materia de medio 
ambiente y paisaje, como estrategias de formación y sensibilización de la ciudadanía, de manera que se consiga una opinión pública activa y con conciencia ambiental.En relación con los objetivos formativos, una de las vías propuestas por el CEP es el desarrollo de cursos escolares y universitarios sobre paisaje (Artículo 6c).

En España, que ratificó el CEP a finales de 2007, la enseñanza del paisaje en el contexto educativo formal es una realidad, ya que tradicionalmente el Diseño Curricular Base y sus currículos autonómicos derivados han incluido contenidos al respecto. No obstante, en lo que respecta a la etapa de Educación Secundaria Obligatoria (ESO), el currículo en vigor no parece incluir el enfoque integrador del CEP en los contenidos de paisaje que presenta (Casas, Puig, y Erneta, 2017a), a pesar de que numerosos autores (sirvan como ejemplo: Busquets, 2002; Castiglioni, 2011; García de la Vega, 2011) y el propio Consejo de Europa (2009) han realizado diversas propuestas al respecto. Y es que el estudio del paisaje, además de un requerimiento del CEP, constituye una gran oportunidad educativa, pues permite abordar de forma integrada contenidos conceptuales propios de diferentes áreas didácticas, potenciándose así la interdisciplinariedad tanto dentro como fuera del aula (Barbadillo, 2016; Liceras, 2003; Sanz y López, 1996). Asimismo, el estudio del paisaje permite fomentar el desarrollo de destrezas y de actitudes de respeto hacia el medio ambiente y la sociedad (Bovet, Pena, y Ribas, 2004; Busquets, 2011; Crespo, 2012).

Volviendo a los cursos escolares como vía para la formación en materia de paisaje, resulta conveniente conocer los conocimientos adquiridos, así como las ideas previas del alumnado para, en base a éstas, diseñar propuestas formativas adecuadas.

En este contexto, el presente estudio tiene por objeto presentar una breve encuesta que ha permitido lograr una aproximación a las ideas previas y representaciones paisajísticas de una muestra del alumnado de Educación Secundaria Obligatoria (12-16 años) de Navarra. En primer lugar, se justifica la elección de la encuesta como instrumento para la recogida de información y se discuten algunos de los ítems de ésta. En segundo lugar, se muestran los principales resultados obtenidos tras la aplicación piloto de la encuesta, que se refieren tanto a aspectos de cumplimentado de la misma, como a la información obtenida en algunas de las preguntas. Por último, se plantea una nueva versión de la encuesta y se presentan brevemente dos propuestas didácticas sobre paisaje diseñadas a partir de la información que se obtuvo en esta aplicación piloto.

\section{METODOLOGÍA}

A continuación, se exponen y discuten los criterios empleados para la selección del grupo de estudio y del instrumento de recogida de datos, así como las preguntas concretas planteadas en este último y el diseño experimental aplicado. 


\subsection{Elección del grupo de estudio y del instrumento de recogida de datos}

Los motivos que han llevado a elegir el alumnado de ESO (12-16 años) como objeto de estudio han sido dos. Por una parte, el hecho, ya mencionado, de que en esta etapa educativa se estudie, por exigencia normativa, el paisaje; por otra, el marco personal de los estudiantes: la adolescencia (Figura 1). Se trata de una etapa vital importante, pues en ella el sujeto adquiere nuevas capacidades, que le permiten construir sus propias ideas y analizar críticamente la realidad que le rodea. Desde este punto de vista, la adolescencia es un período especialmente adecuado para la adquisición de ideales personales y sociales que les lleven a involucrarse en los problemas relacionados con el medio ambiente y la sociedad (López, 1995).

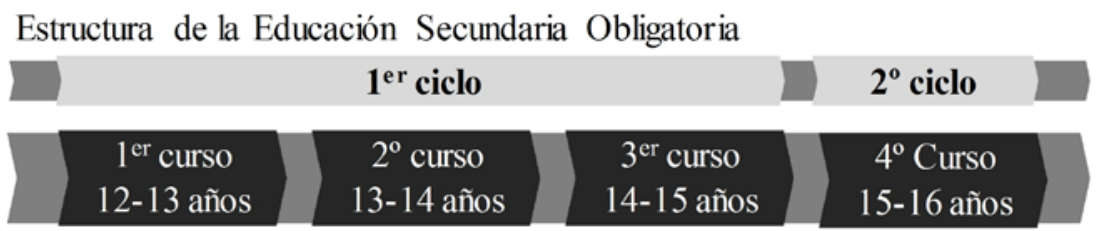

FIgura 1. Edad de los alumnos en la ESO.

Fuente: elaboración propia a partir de: Ley Orgánica 8/2013, de 9 de diciembre.

En cuanto al instrumento de recogida de datos, teniendo en cuenta las características del grupo de estudio elegido (que, en principio, por su edad, podría tener una buena comprensión oral y escrita) la técnica más apropiada -y extendida en investigación educativa- para la recogida de grandes volúmenes de datos es la encuesta (Bisquerra, 2014; Cohen, Manion, y Morrison, 2011).

\subsection{Diseño de la encuesta}

En el diseño de la encuesta se consideraron varios aspectos clave: el perfil del encuestado, el contexto en el que se iba a aplicar la encuesta y la fiabilidad de la misma.

En relación con el perfil del encuestado, se tuvo en cuenta su edad (12-16 años), que condicionaba el lenguaje empleado, el tipo de preguntas (de respuesta abierta o cerrada) y la extensión de la encuesta. Esta última cuestión, además, se vio influida por el ámbito de aplicación de la encuesta, el educativo, ya que el tiempo de cumplimentado disponible era de aproximadamente 15 minutos, es decir, una cuarta parte de una sesión ordinaria del horario lectivo (55 minutos).

Por último, en relación con la fiabilidad de la herramienta, se tomó la precaución de someterla tanto a una evaluación externa, en la que participaron dos expertos con amplia 
experiencia docente e investigadora en materia de paisaje y en el ámbito educativo formal, como a una interna, a través de un diseño de aplicación piloto en varias fases. Fruto del proceso de evaluación externa, que dio lugar a cuatro borradores diferentes de la encuesta, se obtuvo una versión consensuada de ésta -a la que se hará referencia más adelante como Encuesta 0-, que se testó con 268 sujetos (ver apartado 2.3.). Tras esta primera aplicación se introdujeron una serie de modificaciones que dieron lugar a la versión final de la encuesta (Encuesta 1). Ésta última, como se verá en detalle más adelante, se testó en otras tres ocasiones, incluyendo a alumnos de todos los cursos de ESO, residentes tanto en zonas rurales como urbanas.

Teniendo presentes las consideraciones descritas y buscando siempre la brevedad y la sencillez en su cumplimentado se optó por un cuestionario dirigido de seis preguntas (Figura 2). Algunas de ellas eran cerradas, de respuesta prefijada, y otras abiertas, en las que el alumno debía añadir información. Además, en algunas preguntas se incluyó una opción de respuesta abierta, "otros", que permitía al alumnado añadir observaciones y respuestas no preestablecidas. En esta línea, cabe destacar que no se incluyó la opción de respuesta "ninguna de las anteriores" ya que se pensó que los alumnos podrían dar prioridad a ésta en aquellas preguntas en las que también estuviera la opción "otros", consiguiéndose así menos información.

Antes de explicar en detalle las preguntas es preciso mostrar cómo se procedía durante la aplicación piloto, para entender mejor la intención con la que se han formulado las preguntas. En primer lugar, tras presentar la encuesta a los alumnos contextualizada en el marco de una investigación, se les pedía que cerraran los ojos y pensaran en un paisaje, el que quisieran. Pasado un minuto se repartían las encuestas y se les daban unas breves instrucciones de cumplimentado: a las preguntas 1 y 2 debían contestar con el paisaje en el que habían pensado, mientras que en el resto de preguntas (3-6) tenían que aportar información sobre lo que sabían acerca de los paisajes en general. También se les indicaba que en cada pregunta podían marcar varias opciones de respuesta y que, en el caso de que su respuesta no fuera una de dichas opciones, tenían que escribirla en la categoría "otros".

Las preguntas 1 y 2 buscaban revelar los componentes más naturales del tipo de paisaje que viene a la mente de un adolescente cuando se le pide que piense en uno, libremente, y sin tener conocimiento de cómo se le va a preguntar al respecto. En adelante, se hará referencia a este paisaje como paisaje evocado. En caso de conocer o haber visitado el paisaje evocado, se solicitaba al alumno que indicase su localización geográfica. De este modo, la pregunta 1 arrojaba información indirecta acerca de las representaciones paisajísticas de los alumnos, mientras que la pregunta 2 permitía conocer si el paisaje evocado por el alumno hacía referencia a uno real o incluso a uno de sus paisajes cotidianos o próximos. 
Antes de empezar...

- La encuesta es anónima, pero tu curso, localidad e instituto son datos importantes.

- Marca tus respuestas claramente (囚), si te equivocas no pasa nada, bórrala o táchala e indica tu nueva respuesta.

Curso:

Localidad:

Instituto:

1- ¿Cuáles de los siguientes elementos del paisaje están presentes en el que has pensado? Pueden ser más de uno y si no aparecen, escríbelos en la casilla "Otros".

a. Relieve e hidrología:
$\square$ Montaña
$\square$ Llanura
$\square$ Valle/Barranco
Río/Lago
$\square$ otros:

b. Vegetación:

$\square$ Bosque $\square$ Campo sin cultivar $\square$ Campo de cultivo $\square$ Huerta $\quad \square$ Jardín

$\square$ Otros:

c. Fauna:

$\square$ Salvaje (zorro, jabali, águila, serpiente, rana, salamandra, peces...)

$\square$ Animales de ganadería (oveja, cerdo, caballo, vaca...)

$\square$ Mascotas (perro, gato, cobaya...)

2- ¿Has pensado en algún paisaje que conoces o en el que has estado? $\square$ Sí $\square$ No

Si la respuesta es "Si", indica por favor la localidad donde se encuentra y, si se trata de, por ejemplo, un Parque Doblar Natural, indica también su nombre (Ej. Las Bardenas): por aquí

$\downarrow$

Recuerda que a partir de aquí NO tienes que contestar con el paisaje que has pensado, sino con lo que sabes

3- ¿Cuáles de los siguientes elementos crees que pueden formar parte de los paisajes?

$\square$ Edificios (viviendas, tiendas, escuelas, hospitales, fábricas...)

$\square$ Medios de transporte (coche, moto, autobús...)

$\square$ Elementos contaminantes (residuos, humos, ruidos, olores...)

$\square$ Elementos tecnológicos (antenas de TV, placas solares, molinos...)

$\square$ Grandes obras humanas (carreteras, embalses, poligonos industriales, acequias y regadio...)

$\square$ Elementos culturales (castillos, catedrales, monumentos...)

$\square$ Otros:

4- ¿Cómo percibes el paisaje? A través de...

$\square$ Vista $\square$ Oído $\square$ Olfato $\square$ Tacto $\square$ Gusto

5- El ser humano...

$\square$ Es alguien que mira el paisaje

$\square$ Forma parte del paisaje

$\square$ Sus acciones forman parte del paisaje

6- Por último, ¿̇has aprendido sobre paisaje en...?

$\square$ Clases en colegio/instituto

$\square$ Charlas/Talleres

Televisión/Internet

$\square$ Excursiones del colegio/instituto

$\square$ Centros de interpretación/museos

$\square$ En la familia/amigos $\rightarrow$ Si respondes esta opción: ¿ $\underline{\text { QUÉ }}$ te ha enseñado?

$\square$ Otros (p. ej. Grupos Scout, campamentos...):

¡iGRACIAS POR AYUDAR A CREAR CONOCIMIENTO!! @

FIgURA 2. Encuesta aplicada en esta investigación (Encuesta 1).

Fuente: elaboración propia. 
Las preguntas 3, 4 y 5 querían indagar sobre el conocimiento que el alumno tiene sobre el paisaje en general, es decir, no limitado a un único caso o ejemplo como sucedía con el paisaje evocado (preguntas 1 y 2). Estas ideas previas sobre paisaje pueden ser fruto tanto del aprendizaje en el colegio como de su experiencia vital. En este sentido, como se ha comentado anteriormente, se indicaba a los alumnos que a estas preguntas ya no debían responder teniendo en cuenta el paisaje evocado u otro en concreto, sino cualquier posible paisaje, la idea misma de paisaje. En la pregunta 3 se enumeraban algunos posibles elementos del paisaje que son consecuencia de la presencia del ser humano en el mismo (casas, carreteras, coches, ruidos, malos olores, humos...). En la pregunta 4 se abordaba el tema de la percepción del paisaje a través de los sentidos, para determinar cuál de ellos era considerado por los encuestados como el más relevante en la percepción; y con la pregunta 5 se quería averiguar su opinión acerca del papel atribuido al ser humano en relación con el paisaje: observador, modelador o constituyente.

Por último, con la pregunta 6 se buscaba conocer cuáles eran las fuentes a partir de las cuales el adolescente había aprendido sobre paisaje. Se ofrecían algunas opciones de respuesta propias del ámbito de la educación formal (colegio/instituto), de la no formal (charlas, museos...) y de la informal (familia, internet...).

\subsubsection{Justificación de la elección de algunos ítems de la encuesta}

Como se ha comentado anteriormente, dadas las características en las que se enmarcaba el estudio, se optó por un cuestionario dirigido con respuestas prefijadas. Si bien los sujetos encuestados podían añadir información propia, el hecho de que las opciones de respuesta estuvieran ya preestablecidas podía traer consigo un problema de sesgo en la recopilación de la información. Para tratar de reducir el sesgo que toda propuesta de encuesta puede introducir, se pensaron a conciencia las preguntas y sus opciones de respuesta, sopesando las ventajas y desventajas de diferentes posibilidades. A continuación, se justifica la elección de los ítems de las preguntas 1 y 3, que son las que mayor posibilidad de discusión ofrecen.

En cuanto a la pregunta 1, las opciones de respuestas, centradas en los aspectos más naturales de los paisajes, se plantearon a partir de los resultados observados en algunas investigaciones recogidas en la literatura académica. Los estudios de fotopares llevados a cabo por González-Bernáldez y sus colaboradores revelaron hace ya tres décadas la preferencia paisajística de los niños por los paisajes naturales y salvajes, en contraposición a los paisajes humanizados (Benayas, 1992; Bernáldez, Gallado, y Abello, 1987). Años después, Álvarez y Rubio (1996) advirtieron que incluso los alumnos que viven en medios urbanos, tienden a identificar el paisaje con la naturaleza. 
En esta línea, Souto (1996) constató en sus estudios con alumnado de ESO que estos sujetos presentan con frecuencia una visión distorsionada y reduccionista del paisaje, en la que "paisaje" se identifica con "paisaje natural" o "naturaleza". Posteriormente, Adrados (1998) verificó que esta concepción estereotipada del paisaje se encuentra ya en niños de Educación Primaria, quienes además, consideraban el paisaje como algo ajeno al ser humano. Similares resultados obtuvieron poco después Tonda y Sebastiá (2000). Y es que a estas edades, la interpretación del paisaje que hacen los niños se basa en ideas propias firmes y no exentas de prejuicios (García y Benavides, 1996). Por todo ello, en la pregunta 1 únicamente se incluyeron como opciones de respuesta las típicas del paisaje natural y el rural, aun a sabiendas de que otro tipo de paisajes podría aparecer gracias a la respuesta abierta "otros".

Las respuestas de la pregunta 1 se dividieron en tres secciones: relieve e hidrología (1a), vegetación (1b) y fauna (1c). En la sección 1a se decidió presentar de forma conjunta las opciones de respuesta relativas al relieve y a la hidrología. Para el primer caso se optó por tres formas de relieve típicas, a la par que contrastadas: "montaña", "llanura" y "valle/barranco". En el caso de la hidrología solo se ofreció una opción de respuesta, "río/lago", que el alumno marcaría si su paisaje tenía cualquiera de los dos tipos de masas de agua.

Respecto a la sección 1b, sobre vegetación, se incluyeron tres opciones de respuesta propias de los paisajes rurales: "campo sin cultivar", "campo de cultivo" y "huerta". Esta última se pensó especialmente para los alumnos que residían en zonas rurales, pues la huerta es un elemento paisajístico con gran importancia en Navarra. Por otro lado, se decidió incluir la opción "jardín”, por si los alumnos evocaban un paisaje con zonas ajardinadas, propio, por ejemplo, de parques urbanos.

En cuanto a la sección 1c, sobre fauna, es preciso aclarar el porqué de su consideración en esta encuesta. La fauna es un elemento móvil del paisaje y, por tanto, es coherente pensar que cuando se pide al alumno que evoque un paisaje, lo que imagine sea una imagen estática, una "fotografía", del mismo. Por este motivo, es probable que la fauna no estuviera presente, a priori, en esos paisajes evocados, pero que, tras leer en el cuestionario las respuestas al respecto, los alumnos decidieran seleccionar el tipo de fauna que más se adecuara a su paisaje. Se introdujo, por tanto, un sesgo intencional en esta pregunta, ya que la información que aportaría resultaría esencial, como se verá más adelante (apartado 2.4.), para la posterior caracterización de los paisajes evocados por los alumnos. Por último, la opción de respuesta "mascotas" se incluyó para dar cabida también a la fauna con la que el alumnado estaría más familiarizado y podría figurarse, indirectamente, en el paisaje que evocara. Las mascotas, por definición, están ligadas al ser humano, de modo que, si los alumnos marcaban esta opción, incluirían un elemento, en cierto modo propio, en la comprensión de sus paisajes evocados. 
Por último, para reducir en gran medida el sesgo que pudiera introducir el hecho de que las opciones de respuesta prefijadas hicieran referencia fundamentalmente a los paisajes naturales y rurales ${ }^{3}$, se tomaron dos precauciones. En primer lugar, se añadió en las secciones a y b la opción de respuesta abierta "otros", de modo que los sujetos encuestados pudieran añadir información y nuevos descriptores para sus paisajes evocados, como por ejemplo, los propios de paisajes urbanos o periurbanos. No se hizo así en la sección 1c, ya que, como se ha comentado, la información sobre la fauna era relevante para la posterior caracterización de los paisajes evocados, de manera que se quería evitar que los alumnos se decantaran por esa opción frente a las demás. En segundo lugar, como se ha comentado anteriormente, se pedía a los alumnos que evocaran un paisaje antes de repartirles el cuestionario, de manera que los paisajes evocados no se verían influenciados por las opciones de respuesta.

En cuanto a la justificación de la pregunta 3, como se ha avanzado anteriormente, las opciones de respuesta únicamente hacían referencia a elementos humanos del paisaje. Se decidió no ofrecer opciones de respuesta sobre los elementos naturales del paisaje por dos motivos. En primer lugar, porque, en base a las experiencias previas descritas, era probable que los alumnos se decantaran por esas opciones, relegando a un segundo plano a los elementos humanos. En segundo lugar, porque así se podría comprobar si los alumnos realmente echaban en falta esa opción de respuesta, hecho que podría verse reflejado a través de la opción abierta "otros".

\subsection{Aplicación piloto de la encuesta}

En la aplicación piloto de la encuesta participaron 1096 estudiantes de $1^{\circ}$ a $4^{\circ}$ de la ESO de siete centros educativos de la Comunidad Foral de Navarra, los cuales se localizaban en zonas rurales y urbanas (Figura 3). Es evidente que estos centros, que fueron los que amablemente aceptaron participar en el estudio, no representan a todo el alumnado navarro, de modo que los resultados obtenidos no son generalizables. No obstante, la muestra empleada sí resultaba adecuada para esta investigación, en la que se pretendía comprobar si la encuesta diseñada era adecuada para obtener información sobre las ideas previas sobre paisaje y las representaciones paisajísticas de adolescentes (12-16 años) navarros. Se trata, por tanto, de una primera aproximación, que permitirá sentar las bases para un futuro estudio más amplio.

3 En este sentido, es preciso recalcar que los ítems de la encuesta no se han planteado en base a la concepción de paisaje propuesta por el CEP (apartado 1), sino teniendo en cuenta resultados empíricos, que apuntan a que los alumnos tienen una idea estereotipada de paisaje. 


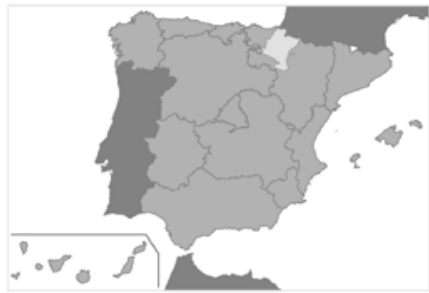

ZONA

URBANA 3

Colegio Hijas de Jesús

(Pamplona)

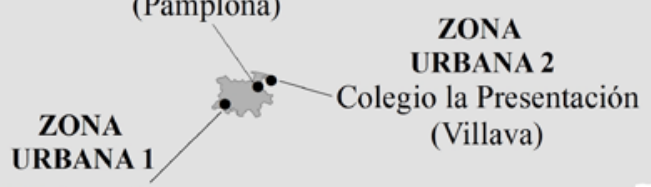

IES Barañáin

(Barañáin)

\section{ZONA}

RURAL 3

IES Sierra de Leyre

(Sangüesa)

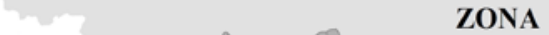

ZONA

RURAL 1

RURAL 2

IESO Reyno de Navarra

(Azagra)

IES Marqués de Villena

(Marcilla)

IES Ribera del Arga

(Peralta)

\begin{tabular}{|c|c|c|c|c|c|c|c|}
\hline \multirow{2}{*}{ Curso } & \multirow{2}{*}{$\begin{array}{c}\text { Fase } \\
\text { aplicación }\end{array}$} & \multirow{2}{*}{$\begin{array}{c}\text { Zona } \\
\text { encuestada }\end{array}$} & \multicolumn{4}{|c|}{ Sujetos encuestados por curso } & \multirow{2}{*}{$\begin{array}{c}\text { Total } \\
\text { encuestados } \\
\text { por zona }\end{array}$} \\
\hline & & & $1^{\circ} \mathrm{ESO}$ & $2^{\circ} \mathrm{ESO}$ & $3^{\circ} \mathrm{ESO}$ & $4^{\circ} \mathrm{ESO}$ & \\
\hline $2012-2013$ & Fase 1 & Zona rural 1 & 0 & 0 & 140 & 128 & 268 \\
\hline 2013-2014 & Fase 2 & Zona urbana 1 & 53 & 69 & 60 & 21 & 203 \\
\hline \multirow{2}{*}{ 2014-2015 } & \multirow{2}{*}{ Fase 3} & Zona rural 2 & 31 & 20 & 48 & 26 & 125 \\
\hline & & Zona rural 3 & 85 & 59 & 43 & 35 & 222 \\
\hline \multirow{2}{*}{ 2016-2017 } & \multirow{2}{*}{ Fase 4} & Zona urbana 2 & 28 & 36 & 23 & 29 & 116 \\
\hline & & Zona urbana 3 & 38 & 34 & 49 & 41 & 162 \\
\hline \multicolumn{3}{|c|}{ Total encuestados por curso } & 235 & 218 & 363 & 280 & 1096 \\
\hline
\end{tabular}

FiguRA 3. Localización de los centros educativos que participaron en el estudio. Fuente: elaboración propia. 
La aplicación piloto se dividió en cuatro fases, que se llevaron a cabo entre 2013 y $2017^{4}$. En la Fase 1 se encuestó a 286 alumnos de $3^{\circ}$ y $4^{\circ}$ de ESO, con el objetivo de testar si los ítems elegidos y el diseño del cuestionario eran apropiados para sujetos de 14 a 16 años (Encuesta 0 ). A partir de los resultados obtenidos en esta primera aplicación, que sirvió a modo de diagnóstico, se elaboró una segunda versión de la encuesta (Encuesta 1), que no implicó modificación de las preguntas ni de las opciones de respuesta, sino la incorporación de unas breves instrucciones de cumplimentado y de mejoras tipográficas.

En la Fase 2 de la aplicación piloto, en la que participaron 203 sujetos, se decidió abordar al mismo tiempo si el diseño de la encuesta era adecuado tanto para alumnos de $1^{\circ}$ y $2^{\circ}$ de ESO (12-14 años) como para aquellos que residían en entornos urbanos o periurbanos. En caso afirmativo, esta encuesta podría emplearse en toda la etapa $\left(1^{\circ}-4^{\circ}\right.$ de ESO) y en zonas rurales y urbanas, sin necesidad de introducir modificaciones.

Por último, en las Fases 3 y 4 se amplió el estudio a otras dos zonas rurales (347 sujetos) y otras dos urbanas (278), de modo que el tamaño muestral final permitiera obtener resultados fiables.

\subsection{Tratamiento de datos y revisión de ítems}

Las respuestas de los sujetos de estudio se recopilaron en una base de datos, agrupadas por tipo de pregunta, curso, centro educativo y localización de éste (especificando si pertenecía a una zona rural o una urbana). A continuación, se realizó un análisis de los siguientes aspectos de cumplimentado: el número de respuestas válidas por pregunta, las preguntas en blanco e incompletas y la multiplicidad de respuestas. Tras eliminar las preguntas no válidas y las que estaban en blanco se obtuvo un valor total para cada pregunta, a partir del cual se calcularon los porcentajes de respuesta.

En el caso de la pregunta 1, tras analizar las respuestas de los alumnos, se identificaron diferentes tipos de paisajes evocados, motivo por el cual se definieron seis tipologías generales (Tabla 1), en las que posteriormente se clasificaron dichos paisajes.

En cuanto a la pregunta 2, se revisaron las localizaciones señaladas por los alumnos para sus paisajes evocados, completando, en algunos casos, la información con la ayuda de Google Maps y de la Infraestructura de Datos Espaciales de Navarra (IDENA).

4 Durante los cursos 2015-2016 y 2016-2017 se produjo la implantación de la Ley Orgánica para mejora de la calidad educativa en la ESO, hecho que no debería haber afectado a las ideas de los alumnos sobre paisaje, pues el background de conocimientos de todos los encuestados procedía de cursos anteriores, cuando la Ley Orgánica de Educación (LOE) estaba vigente. 


\begin{tabular}{|c|c|c|}
\hline $\begin{array}{c}\text { Tiplogias de } \\
\text { paisajes evocados }\end{array}$ & Descripción de la tipologia & $\begin{array}{c}\text { Descriptores empleados en la } \\
\text { Pregunta } 1\end{array}$ \\
\hline 1. Paisaje natural & $\begin{array}{l}\text { Paisaje donde hay un claro predomi- } \\
\text { nio de los elementos naturales. }\end{array}$ & $\begin{array}{l}\text { 1a) Montaña, río/lago, valle/barranco } \\
\text { 1b) bosque } \\
\text { 1c) fauna salvaje }\end{array}$ \\
\hline 2. Paisaje rural & $\begin{array}{l}\text { Paisajes agrarios y ganaderos: cam- } \\
\text { pos de cultivo, huertas, zonas de pas- } \\
\text { tos, ganaderías... }\end{array}$ & $\begin{array}{l}\text { 1b) campo de cultivo, campo sin cul- } \\
\text { tivar, huerta } \\
\text { 1c) animales de ganadería }\end{array}$ \\
\hline $\begin{array}{l}\text { 3. Paisaje urbano y } \\
\text { periurbano }\end{array}$ & $\begin{array}{l}\text { Paisaje donde hay un claro predomi- } \\
\text { nio de elementos artificiales. Incluye a } \\
\text { las ciudades, sus zonas periurbanas, y } \\
\text { a los cascos urbanos de los pueblos. }\end{array}$ & $\begin{array}{l}\text { Opciones de respuesta no prefijadas, } \\
\text { como: ciudad, pueblo, plaza... }\end{array}$ \\
\hline $\begin{array}{l}\text { 4. Paisaje costero- } \\
\text { litoral }\end{array}$ & $\begin{array}{l}\text { Paisaje propio de zonas litorales: } \\
\text { playa, cala, zona de acantilados, } \\
\text { islas... }\end{array}$ & $\begin{array}{l}\text { Opciones de respuesta no prefijadas, } \\
\text { como: mar, arena, palmeras, algas... }\end{array}$ \\
\hline $\begin{array}{l}\text { 5. Paisaje de infraes- } \\
\text { tructuras energéticas } \\
\text { y de comunicaciones }\end{array}$ & $\begin{array}{l}\text { Parques eólicos, huertas solares, } \\
\text { presas, pantanos, etc. }\end{array}$ & $\begin{array}{l}\text { Opciones de respuesta no prefijadas, } \\
\text { como: molinos, aerogeneradores, pla- } \\
\text { cas solares, presa, embalse... }\end{array}$ \\
\hline 6. Otros & $\begin{array}{l}\text { Paisajes que no encajan en las ca- } \\
\text { tegorías anteriormente descritas. }\end{array}$ & - \\
\hline
\end{tabular}

TABLA 1. Tipologías de paisajes evocados por los alumnos.

\section{RESULTADOS}

A continuación, se muestran los resultados más relevantes tanto del análisis de los aspectos de cumplimentado, como de la información obtenida en las preguntas 1, 2 y 3, que permitirán valorar si el diseño de la encuesta era adecuado y esbozar unas primeras conclusiones en relación con las representaciones paisajísticas y algunas de las ideas previas de los alumnos navarros.

Dado que la Encuesta 0 se modificó tras su aplicación en la Fase 1 (apartado 2.3.), los resultados que se muestran a continuación pertenecen a la Encuesta 1 (Fases 2-4, 828 encuestados). A fin de simplificar la presentación de los mismos, se han agrupado en dos bloques: "zonas rurales", que incluye las zonas rurales 2 y 3 (347 encuestas), y "zonas urbanas", compuesto por las zonas urbanas 1, 2 y 3 (481 encuestas).

\subsection{Aspectos de cumplimentado}

Aunque se han revisado varios aspectos de cumplimentado (apartado 2.4.), solo se recogen aquí aquellos que han tenido mayor incidencia. 


\subsubsection{Respuestas válidas por pregunta}

Al analizar las encuestas se detectaron tres situaciones particulares para las preguntas 1, 2 y 3 en las que se optó por considerarlas no válidas. Las preguntas 1 y 2 se anularon si el alumno respondía con más de un paisaje evocado o las respuestas de la pregunta 1 no eran coherentes con el paisaje indicado en la pregunta 2.

\begin{tabular}{|c|c|c|c|c|c|c|}
\hline \multirow{2}{*}{$\begin{array}{c}\text { Zona } \\
\text { encuestada }\end{array}$} & \multirow{2}{*}{ Pregunta } & \multicolumn{5}{|c|}{ Respuestas } \\
\hline & & No válidas & Válidas & Total & \% no válidas & \% válidas \\
\hline \multirow{7}{*}{$\begin{array}{l}\text { Zona } \\
\text { rural }\end{array}$} & $\mathrm{N}^{\mathrm{o}} 1$ & 11 & 336 & 347 & $3,2 \%$ & $96,8 \%$ \\
\hline & $\mathrm{N}^{\mathrm{o}} 2$ & 11 & 336 & 347 & $3,2 \%$ & $96,8 \%$ \\
\hline & $\mathrm{N}^{\mathrm{o}} 3$ & 8 & 339 & 347 & $2,3 \%$ & $97,7 \%$ \\
\hline & $\mathrm{N}^{\circ} 4$ & 0 & 347 & 347 & $0,0 \%$ & $100,0 \%$ \\
\hline & $\mathrm{N}^{0} 5$ & 0 & 347 & 347 & $0,0 \%$ & $100,0 \%$ \\
\hline & $\mathrm{N}^{\mathrm{o}} 6$ & 0 & 347 & 347 & $0,0 \%$ & $100,0 \%$ \\
\hline & Total & 30 & 2052 & 2082 & $1,4 \%$ & $98,6 \%$ \\
\hline \multirow{7}{*}{ Zona urbana } & $\mathrm{N}^{0} 1$ & 12 & 469 & 481 & $2,5 \%$ & $97,5 \%$ \\
\hline & $\mathrm{N}^{\mathrm{o}} 2$ & 12 & 469 & 481 & $2,5 \%$ & $97,5 \%$ \\
\hline & $\mathrm{N}^{\mathrm{o}} 3$ & 25 & 456 & 481 & $5,2 \%$ & $94,8 \%$ \\
\hline & $\mathrm{N}^{\mathrm{o}} 4$ & 0 & 481 & 481 & $0,0 \%$ & $100,0 \%$ \\
\hline & $\mathrm{N}^{\mathrm{o}} 5$ & 0 & 481 & 481 & $0,0 \%$ & $100,0 \%$ \\
\hline & $\mathrm{N}^{0} 6$ & 0 & 481 & 481 & $0,0 \%$ & $100,0 \%$ \\
\hline & Total & 49 & 2837 & 2886 & $1,7 \%$ & $98,3 \%$ \\
\hline \multicolumn{2}{|c|}{ Total Zona rural + urbana } & 79 & 4889 & 4968 & $1,6 \%$ & $98,4 \%$ \\
\hline
\end{tabular}

TABLA 2. Respuestas válidas por pregunta.

En cuanto a la pregunta 3, se anularon aquellos casos en los que el alumno, aparentemente, había respondido con su paisaje evocado. Generalmente resultó sencillo identificar esta situación, ya que los alumnos añadían información específica en el apartado "otros", que coincidía con la descripción de su paisaje evocado. En los casos que no eran tan evidentes, ante la duda, se decidió considerarlos no válidos.

En la Tabla 2 se puede observar que el 98,4\% de las respuestas de los alumnos fueron válidas. El porcentaje más elevado se obtuvo para la pregunta 3 de la zona urbana $(5,2 \%$ de no válidas), mientras que, en el resto de los casos, los porcentajes no fueron superiores al $3 \%$. Estos resultados son positivos y apuntan a una buena comprensión general de la encuesta.

\subsubsection{Preguntas en blanco}

El total de preguntas válidas que aparecían en blanco en las encuestas fue bajo $(2,4 \%)$ (Tabla 3). 


\begin{tabular}{|c|c|c|c|c|c|c|c|}
\hline \multirow{2}{*}{$\begin{array}{c}\text { Zona } \\
\text { encuestada }\end{array}$} & \multirow{2}{*}{\multicolumn{2}{|c|}{ Pregunta }} & \multicolumn{5}{|c|}{ Respuestas } \\
\hline & & & En blanco & Correctas & Total & $\%$ en blanco & $\%$ correctas \\
\hline \multirow{10}{*}{$\begin{array}{l}\text { Zona } \\
\text { rural }\end{array}$} & & $\mathrm{a}$ & 0 & 336 & 336 & $0,0 \%$ & $100,0 \%$ \\
\hline & $\mathrm{N}^{\circ} 1$ & $\mathrm{~b}$ & 3 & 333 & 336 & $0,9 \%$ & $99,1 \%$ \\
\hline & & $\mathrm{c}$ & 35 & 301 & 336 & $10,4 \%$ & $89,6 \%$ \\
\hline & Total & $\mathrm{N}^{\circ} 1$ & 38 & 298 & 336 & $11,3 \%$ & $88,7 \%$ \\
\hline & $\mathrm{N}^{\circ}$ & & 4 & 332 & 336 & $1,2 \%$ & $98,8 \%$ \\
\hline & $\mathrm{N}^{\circ}$ & & 11 & 328 & 339 & $3,2 \%$ & $96,8 \%$ \\
\hline & $\mathrm{N}^{\circ}$ & & 1 & 346 & 347 & $0,3 \%$ & $99,7 \%$ \\
\hline & $\mathrm{N}^{\mathrm{o}}$ & & 6 & 341 & 347 & $1,7 \%$ & $98,3 \%$ \\
\hline & $\mathrm{N}^{\circ}$ & & 2 & 345 & 347 & $0,6 \%$ & $99,4 \%$ \\
\hline & To & & 62 & 1990 & 2052 & $3,0 \%$ & $97,0 \%$ \\
\hline \multirow{10}{*}{$\begin{array}{c}\text { Zona } \\
\text { urbana }\end{array}$} & & $\mathrm{a}$ & 4 & 465 & 469 & $0,9 \%$ & $99,1 \%$ \\
\hline & $\mathrm{N}^{\circ} 1$ & b & 5 & 464 & 469 & $1,1 \%$ & $98,9 \%$ \\
\hline & & $\mathrm{c}$ & 28 & 441 & 469 & $6,0 \%$ & $94,0 \%$ \\
\hline & Total & $\mathrm{J}^{\circ} 1$ & 37 & 432 & 469 & $7,9 \%$ & $92,1 \%$ \\
\hline & $\mathrm{N}^{\circ}$ & & 3 & 466 & 469 & $0,6 \%$ & $99,4 \%$ \\
\hline & $\mathrm{N}^{\circ}$ & & 7 & 449 & 456 & $1,5 \%$ & $98,5 \%$ \\
\hline & $\mathrm{N}^{\circ}$ & & 0 & 481 & 481 & $0,0 \%$ & $100,0 \%$ \\
\hline & $\mathrm{N}^{0}$ & & 1 & 480 & 481 & $0,2 \%$ & $99,8 \%$ \\
\hline & $\mathrm{N}^{\circ}$ & & 5 & 476 & 481 & $1,0 \%$ & $99,0 \%$ \\
\hline & To & & 53 & 2784 & 2837 & $1,9 \%$ & $98,1 \%$ \\
\hline \multicolumn{3}{|c|}{ Total Zona rural + urbana } & 115 & 4774 & 4889 & $2,4 \%$ & $97,6 \%$ \\
\hline
\end{tabular}

Tabla 3. Preguntas en blanco

No obstante, si se atiende a cada una en particular, se aprecia que la 1 y la 3 son las que presentaban un mayor porcentaje de no respuesta, con un $11,3 \%$ y un 3,2\%, respectivamente, en la zona rural, y un $7,9 \%$ y un $1,5 \%$ en la zona urbana. Además, cabe destacar que, en ambas zonas, el porcentaje de la pregunta 1 se debía en gran medida a su apartado "c" ( $10,4 \%$ en rural y $6 \%$ en urbana).

Los resultados obtenidos para la pregunta 1c podrían deberse a la ausencia de fauna en el paisaje evocado por el alumno, de modo que éste, al no disponer de esa opción de respuesta, habría optado por dejar la pregunta en blanco. Como se ha señalado antes (apartado 2.1.1.), no se incluyó la opción de respuesta "no tiene fauna" porque la información de esta pregunta era relevante para la posterior categorización de los paisajes evocados por los alumnos. No obstante, y dado que los porcentajes de respuesta en blanco fueron elevados, se propondrán medidas al respecto más adelante.

En el caso de la pregunta 3, los resultados obtenidos podrían deberse a que es la cuestión con más opciones de respuesta y texto del cuestionario, hecho que pudo disuadir al alumno de contestarla. 


\subsubsection{Cumplimentado incompleto de preguntas}

Como se puede apreciar en la Tabla 4 , se consideraron por separado los datos de identificación del sujeto (curso, localidad e instituto) y las preguntas 2 y 6 , que eran las únicas en las que se solicitaba información al alumno.

\begin{tabular}{|c|c|c|c|c|c|c|}
\hline \multirow{2}{*}{$\begin{array}{c}\text { Zona } \\
\text { encuestada }\end{array}$} & \multirow[b]{2}{*}{ Pregunta } & \multicolumn{5}{|c|}{ Respuestas } \\
\hline & & $\begin{array}{l}\text { Incom- } \\
\text { pletas }\end{array}$ & $\begin{array}{l}\text { Com- } \\
\text { pletas }\end{array}$ & Total & $\begin{array}{c}\% \text { incom- } \\
\text { pletas }\end{array}$ & $\begin{array}{c}\% \text { com- } \\
\text { pletas }\end{array}$ \\
\hline \multirow{4}{*}{$\begin{array}{l}\text { Zona } \\
\text { rural }\end{array}$} & $\begin{array}{c}\text { Datos de } \\
\text { identificación }\end{array}$ & 4 & 343 & 347 & $1,2 \%$ & $98,8 \%$ \\
\hline & $\mathrm{N}^{\circ} 2$ & 10 & 187 & 197 & $5,1 \%$ & $94,9 \%$ \\
\hline & $\mathrm{N}^{\circ} 6$ & 13 & 101 & 114 & $11,4 \%$ & $88,6 \%$ \\
\hline & Total & 27 & 631 & 658 & $4,1 \%$ & $95,9 \%$ \\
\hline \multirow{4}{*}{$\begin{array}{l}\text { Zona } \\
\text { urbana }\end{array}$} & $\begin{array}{c}\text { Datos de } \\
\text { identificación }\end{array}$ & 8 & 473 & 481 & $1,7 \%$ & $98,3 \%$ \\
\hline & $\mathrm{N}^{\circ} 2$ & 23 & 233 & 256 & $9,0 \%$ & $91,0 \%$ \\
\hline & $\mathrm{N}^{\circ} 6$ & 21 & 155 & 176 & $11,9 \%$ & $88,1 \%$ \\
\hline & Total & 52 & 861 & 913 & $5,7 \%$ & $94,3 \%$ \\
\hline \multicolumn{2}{|c|}{ Total Zona rural + urbana } & 79 & 1492 & 1571 & $5,0 \%$ & $95,0 \%$ \\
\hline
\end{tabular}

TABLA 4. Cumplimentado incompleto de preguntas.

En cuanto a los datos de identificación del sujeto, se observa que la mayoría de los alumnos indicó esta información (más del 98\% en ambas zonas). Además, de los 12 casos detectados en total, 10 se pudieron subsanar, ya que las encuestas se fueron guardando agrupadas por curso, aula y centro a medida que se realizaban; en los dos casos restantes, el sujeto no indicó su localidad de residencia. En relación con este último punto, se ha detectado otro fenómeno que, si bien no aparece reflejado en la tabla, es preciso mencionarlo aquí. En el caso de la Zona rural 3, un 92,3\% de los encuestados (205 de 222) indicaron como su localidad de residencia aquella donde se encontraba el centro educativo. Esta información se contrastó con los docentes del centro, cuya área de influencia abarcaba varios municipios, que confirmaron el error. En consecuencia, no se pudo determinar en la pregunta 2 si la localidad de residencia del alumno y aquella donde se localizaba su paisaje evocado eran coincidentes, de modo que este último pudiera considerarse su paisaje cotidiano.

Respecto a las preguntas del cuestionario, la número 2 se consideró incompleta cuando los alumnos respondían que habían evocado un paisaje que conocían, pero no indicaban su localización o señalaban que no la recordaban. Esta situación se observó en un $5,1 \%$ de casos en la zona rural y en un $9 \%$ en la zona urbana. En cuanto a 
la pregunta 6 se calificó como incompleta cuando los sujetos respondían que habían aprendido sobre paisaje en el ámbito familiar pero no indicaban qué habían aprendido. Este suceso se apreció en un 11,4\% de casos en la zona rural y en un 11,9\% en la zona urbana.

\subsubsection{Multiplicidad de respuestas}

Durante el análisis de aspectos de cumplimentado se apreció la repetición de tres sucesos que implicaban pérdida de información, los cuales se englobaron bajo el título genérico de "multiplicidad de respuestas".

El primer suceso reflejado en la Tabla 5 consiste en que los alumnos respondían con más de un paisaje evocado a las preguntas 1 y 2, situación que se registró de forma similar en las zonas rural $(2,1 \%)$ y urbana $(2,4 \%)$.

\begin{tabular}{|c|c|c|c|c|c|c|c|}
\hline $\begin{array}{l}\text { Zona } \\
\text { encues- } \\
\text { tada }\end{array}$ & Casos & Pregunta & $\begin{array}{c}\mathrm{N}^{\circ} \\
\text { casos }\end{array}$ & $\begin{array}{c}\text { Respuestas } \\
\text { correctas }\end{array}$ & $\begin{array}{l}\text { Total de } \\
\text { respuestas }\end{array}$ & $\begin{array}{l}\% \text { casos } \\
\text { respecto al } \\
\text { total }\end{array}$ & $\begin{array}{c}\% \text { respuestas } \\
\text { correctas } \\
\text { respecto al } \\
\text { total }\end{array}$ \\
\hline \multirow{5}{*}{$\begin{array}{l}\text { Zona } \\
\text { rural }\end{array}$} & 1. Responde sobre & $\mathrm{N}^{\circ} 1$ & 7 & 329 & 336 & $2,1 \%$ & $97,9 \%$ \\
\hline & más de un paisaje & $\mathrm{N}^{\circ} 2$ & 7 & 329 & 336 & $2,1 \%$ & $97,9 \%$ \\
\hline & $\begin{array}{l}\text { 2. Responde con } \\
\text { paisaje evocado }\end{array}$ & $\mathrm{N}^{\circ} 3$ & 8 & 331 & 339 & $2,4 \%$ & $97,6 \%$ \\
\hline & $\begin{array}{l}\text { 3. Responde infor- } \\
\text { mación no solicitada }\end{array}$ & $\mathrm{N}^{\circ} 6$ & 46 & 55 & 101 & $45,5 \%$ & $54,5 \%$ \\
\hline & Total & & 68 & 1044 & 1112 & $6,1 \%$ & $93,9 \%$ \\
\hline \multirow{5}{*}{$\begin{array}{l}\text { Zona } \\
\text { urbana }\end{array}$} & 1. Responde sobre & $\mathrm{N}^{\circ} 1$ & 11 & 458 & 469 & $2,3 \%$ & $97,7 \%$ \\
\hline & más de un paisaje & $\mathrm{N}^{\circ} 2$ & 11 & 458 & 469 & $2,3 \%$ & $97,7 \%$ \\
\hline & $\begin{array}{l}\text { 2. Responde con } \\
\text { paisaje evocado }\end{array}$ & $\mathrm{N}^{\circ} 3$ & 25 & 431 & 456 & $5,5 \%$ & $94,5 \%$ \\
\hline & $\begin{array}{l}\text { 3. Responde infor- } \\
\text { mación no solicitada }\end{array}$ & $\mathrm{N}^{\circ} 6$ & 72 & 83 & 155 & $46,5 \%$ & $53,5 \%$ \\
\hline & Total & & 119 & 1430 & 1549 & $7,7 \%$ & $92,3 \%$ \\
\hline \multicolumn{2}{|c|}{ Total Zona rural + urbana } & & 187 & 2474 & 2661 & $7,0 \%$ & $93,0 \%$ \\
\hline
\end{tabular}

Tabla 5. Multiplicidad de respuestas.

En el segundo caso, los sujetos respondían a la pregunta 3 con su paisaje evocado, fenómeno que se dio en un 5,5\% de casos en la zona urbana y en un 3,5\% en la rural.

La tercera situación consiste en que los alumnos no respondían acerca de qué habían aprendido sobre paisaje en el ámbito de la familia/las amistades (pregunta 6), sino que aportaban otra información (dónde habían aprendido, con quién, cuándo, etc.). 
Casi la mitad de los alumnos (45,5\% en zona rural y 46,5\% en urbana) no respondió adecuadamente a esta pregunta. Este porcentaje tan elevado, unido al de sujetos que no cumplimentaban esta sección de la pregunta (Tabla 4: 11,4\% zona rural; 11,9\% urbana), señala la necesidad de reconsiderar la formulación de la misma.

Las dos primeras situaciones descritas se corresponden con los criterios empleados para calificar como "no válidas" las preguntas 1, 2 y 3 (ver apartado 3.1.1.). Como se puede observar en la Tabla 6, la multiplicidad era en gran medida la responsable de las respuestas no válidas para las preguntas 1 y 2 (70\% en zona rural y $91,7 \%$ en zona urbana) y explicaba el $100 \%$ de los casos observados para la pregunta 3 .

\begin{tabular}{|c|c|c|c|c|c|}
\hline $\begin{array}{c}\text { Zona } \\
\text { encuestada }\end{array}$ & $\begin{array}{c}\text { Casos } \\
\text { multiplicidades }\end{array}$ & Preguntas & $\begin{array}{c}\mathrm{N}^{\circ} \\
\text { casos }\end{array}$ & $\begin{array}{c}\text { Total } \\
\text { no } \\
\text { válidas }\end{array}$ & $\begin{array}{c}\% \text { no } \\
\text { válidas } \\
\text { debido a }\end{array}$ \\
\hline \multirow{4}{*}{$\begin{array}{l}\text { Zona } \\
\text { rural }\end{array}$} & 1. Responde sobre & $\mathrm{N}^{\circ} 1$ & 7 & 11 & $63,6 \%$ \\
\hline & más de un paisaje & $\mathrm{N}^{\circ} 2$ & 7 & 11 & $63,6 \%$ \\
\hline & $\begin{array}{l}2 . \text { Responde con } \\
\text { paisaje evocado }\end{array}$ & $\mathrm{N}^{\circ} 3$ & 8 & 8 & $100 \%$ \\
\hline & Total & & 22 & 30 & $73,3 \%$ \\
\hline \multirow{4}{*}{$\begin{array}{c}\text { Zona } \\
\text { urbana }\end{array}$} & 1. Responde sobre & $\mathrm{N}^{0} 1$ & 11 & 12 & $91,7 \%$ \\
\hline & más de un paisaje & $\mathrm{N}^{\circ} 2$ & 11 & 12 & $91,7 \%$ \\
\hline & $\begin{array}{l}\text { 2. Responde con } \\
\text { paisaje evocado }\end{array}$ & $\mathrm{N}^{\circ} 3$ & 25 & 25 & $100 \%$ \\
\hline & Total & & 47 & 49 & $95,9 \%$ \\
\hline \multicolumn{3}{|c|}{ Total Zona rural + urbana } & 69 & 79 & $87,3 \%$ \\
\hline
\end{tabular}

TABla 6. Respuestas no válidas debido a la multiplicidad de respuestas.

\subsection{Respuestas de las preguntas}

A continuación, se muestran los principales resultados obtenidos para las preguntas 1 y 2 , sobre los paisajes evocados por los alumnos, y la número 3 , acerca de los elementos humanos del paisaje.

\subsubsection{Pregunta 1}

Los paisajes evocados por los alumnos se muestran en el Gráfico 1. Tal y como se preveía, el tipo de paisaje más evocado fue el natural $(49,2 \%)$; seguido, aunque a distancia, por los paisajes rurales $(20,9 \%)$ y los costeros $(14,5 \%)$. En contraposición, los paisajes menos elegidos fueron el urbano $(2,9 \%)$ y el de infraestructuras energéticas y telecomunicaciones $(1,9 \%)$. 
Al separar los paisajes evocados en función de la zona de residencia del alumno (rural o urbana) se observaron los mismos patrones de respuesta, aunque los porcentajes varían según la tipología. En la zona rural el paisaje natural obtuvo un valor $11,7 \%$ más alto que en la urbana. Sin embargo, el porcentaje de respuesta para los paisajes rurales y los costeros era, respectivamente, un $3,2 \%$ y un $6,1 \%$ superior en la zona urbana que en la rural. En cuanto a la tipología de paisajes urbanos, el porcentaje observado era bajo en ambos casos ( $1,8 \%$ en zona rural y $3,9 \%$ en zona urbana).
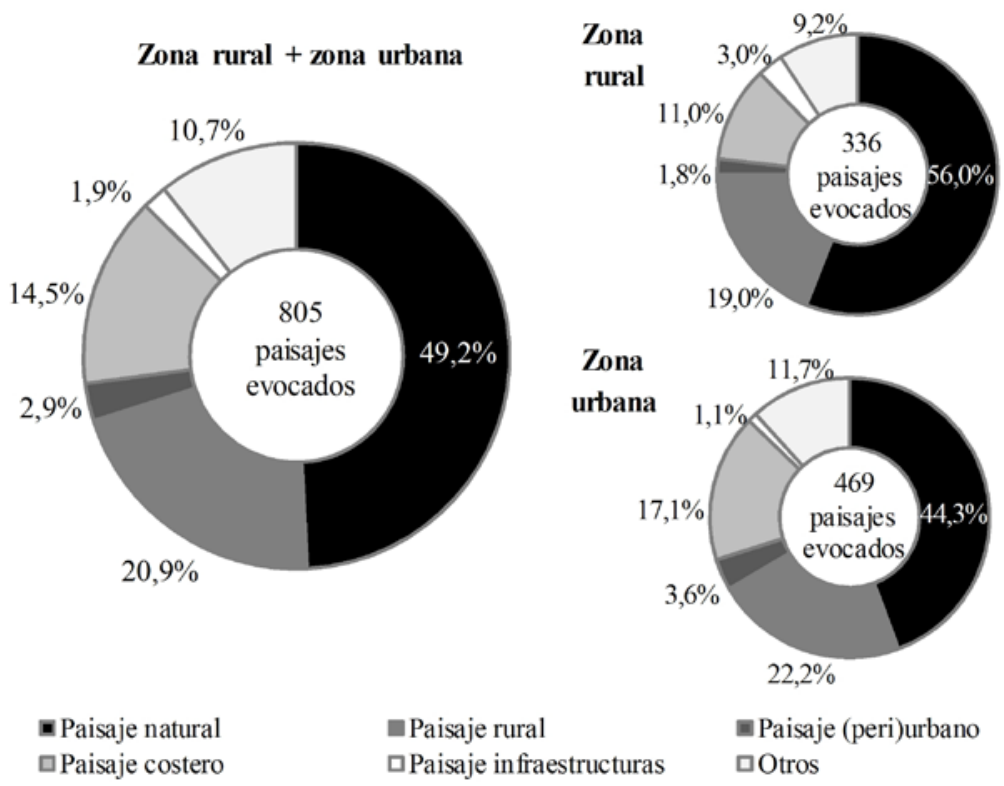

Gráfico 1. Tipologías de paisajes evocados por los alumnos.

Los resultados obtenidos en esta pregunta son coherentes con los observados en los estudios anteriormente descritos (apartado 2.2.1.) y apoyan la hipótesis de partida sobre la preferencia de los alumnos por los paisajes naturales. Por otro lado, el hecho de que un $14,5 \%$ de los encuestados haya descrito un paisaje costero a pesar de no tener en la encuesta respuestas específicas para ello, indica que la opción abierta "otros" ha cumplido su función correctamente.

En cuanto a la tipología de paisaje evocado denominada "otros", que obtuvo un 9,2\% en la zona rural y un $11,7 \%$ en la urbana, en la Tabla 7 se aprecia que las opciones de respuesta más elegidas fueron "jardín” (18\%) y "mascotas" (16 \%). No obstante, al analizar los paisajes incluidos en esta tipología, da la impresión de que "jardín" no se ha empleado en el sentido esperado, es decir, para describir una zona ajardinada, más propia 
de parques urbanos, sino que más bien se ha utilizado como prado o pasto, elementos presentes en paisajes más naturalizados. Esto podría deberse a que los alumnos no son conscientes de la diferencia entre pasto y jardín y utilizan los términos indistintamente para referirse a ambas realidades. En cuanto a la opción de respuesta "mascotas", cuando ésta aparecía como única respuesta de su categoría (sección 1c), no permitía la clasificación del paisaje en ninguna de las tipologías paisajísticas definidas, de modo que pasaba a engrosar la titulada como "Otros". Por todo lo expuesto, es necesario reconsiderar las opciones de respuesta "jardín” y "mascotas".

\begin{tabular}{|c|c|c|c|}
\hline Pregunta 1 & $\begin{array}{c}\text { Opciones de } \\
\text { respuesta }\end{array}$ & $\mathrm{n}^{\circ}$ casos & $\%$ casos \\
\hline \multirow{3}{*}{ Sección 1a } & Montaña & 20 & $7,8 \%$ \\
\hline & Llanura & 26 & $10,2 \%$ \\
\hline & Río/Lago & 32 & $12,5 \%$ \\
\hline \multirow{2}{*}{ Sección $1 b$} & $\begin{array}{l}\text { Campo sin } \\
\text { cultivar }\end{array}$ & 32 & $12,5 \%$ \\
\hline & Jardín & 46 & $18,0 \%$ \\
\hline \multirow{2}{*}{ Sección 1c } & Mascotas & 41 & $16,0 \%$ \\
\hline & Fauna salvaje & 37 & $14,5 \%$ \\
\hline \multicolumn{2}{|c|}{ Otras respuestas $(<3,5 \%)$} & 22 & $8,6 \%$ \\
\hline \multicolumn{2}{|c|}{ Total } & 256 & $100,0 \%$ \\
\hline
\end{tabular}

TABLA 7. Tipología de paisajes evocados "Otros": opciones de respuesta empleadas por los alumnos para describirlo.

\subsubsection{Pregunta 2}

El 56,1\% de los paisajes evocados por los alumnos eran paisajes que, según señalaban los encuestados, conocían o habían visitado en alguna ocasión (Figura 4). La mayoría de dichos paisajes se localizaban en España $(86,6 \%)$ y más de la mitad de éstos en la Comunidad Foral de Navarra (57\%).

Por otra parte, tal y como se puede observar en la Tabla 8 , las provincias que mayor número de casos presentaron, después de Navarra, fueron las limítrofes con ésta: Guipúzcoa, Zaragoza y Huesca. También destacaron Cantabria y Asturias, así como Tarragona, Castellón y Alicante, representantes, respectivamente, de las costas cantábrica y mediterránea. Todas estas provincias, junto con Soria, aglutinaban el 86,6\% de los paisajes evocados que incluían información geográfica suficiente para su localización a nivel provincial. 


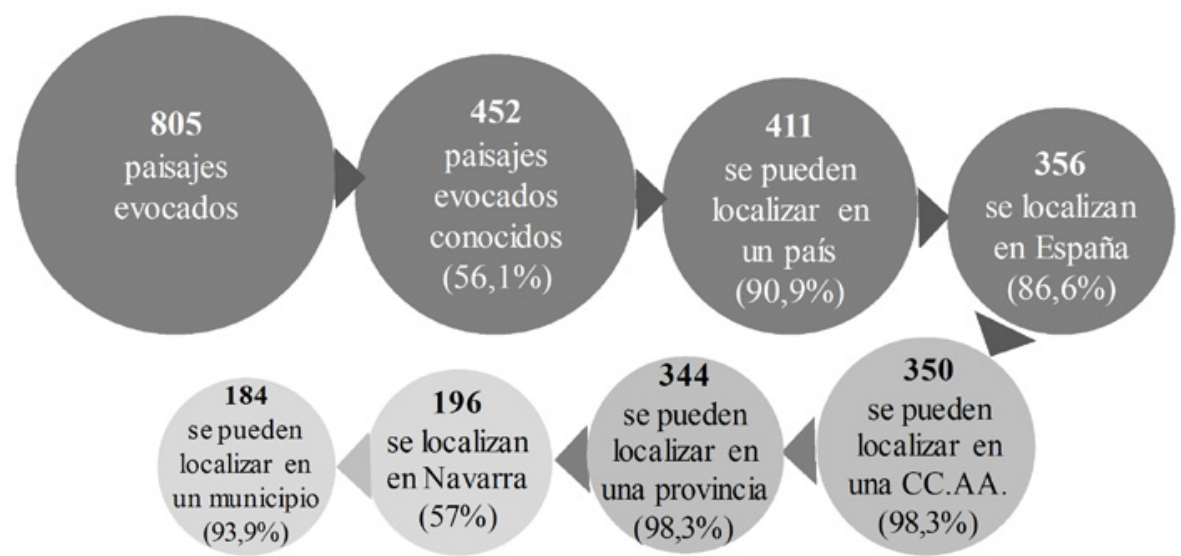

Figura 4. Datos sobre la localización de los paisajes evocados a distintas escalas geográficas. Fuente: elaboración propia.

\begin{tabular}{lcc|cccccc}
\hline Provincias & $\mathrm{n}^{\circ}$ & $\begin{array}{c}\% \text { casos } \\
\text { de Especto }\end{array}$ & \multicolumn{5}{c}{$\%$ Paisajes evocados por provincia } \\
& casos & total & Paisaje & Paisaje & Paisaje & Paisaje & $\begin{array}{c}\text { Paisaje de } \\
\text { infraes- }\end{array}$ & Otros \\
natural & rural & urbano & costero & & \\
tructuras & \\
\hline Zaragoza & 17 & $4,9 \%$ & $64,7 \%$ & $23,5 \%$ & $5,9 \%$ & $0,0 \%$ & $5,9 \%$ & $0,0 \%$ \\
Guipúzcoa & 16 & $4,7 \%$ & $12,5 \%$ & $0,0 \%$ & $0,0 \%$ & $87,5 \%$ & $0,0 \%$ & $0,0 \%$ \\
Huesca & 16 & $4,7 \%$ & $81,3 \%$ & $6,3 \%$ & $0,0 \%$ & $0,0 \%$ & $6,3 \%$ & $6,3 \%$ \\
Castellón & 12 & $3,5 \%$ & $0,0 \%$ & $0,0 \%$ & $8,3 \%$ & $91,7 \%$ & $0,0 \%$ & $0,0 \%$ \\
Tarragona & 11 & $3,2 \%$ & $0,0 \%$ & $0,0 \%$ & $18,2 \%$ & $81,8 \%$ & $0,0 \%$ & $0,0 \%$ \\
Cantabria & 10 & $2,9 \%$ & $50,0 \%$ & $10,0 \%$ & $0,0 \%$ & $40,0 \%$ & $0,0 \%$ & $0,0 \%$ \\
Asturias & 8 & $2,3 \%$ & $50,0 \%$ & $25,0 \%$ & $0,0 \%$ & $12,5 \%$ & $0,0 \%$ & $12,5 \%$ \\
Alicante & 6 & $1,7 \%$ & $33,3 \%$ & $0,0 \%$ & $0,0 \%$ & $66,7 \%$ & $0,0 \%$ & $0,0 \%$ \\
Soria & 6 & $1,7 \%$ & $66,7 \%$ & $33,3 \%$ & $0,0 \%$ & $0,0 \%$ & $0,0 \%$ & $0,0 \%$ \\
\hline Total & 298 & $86,6 \%$ & $54,0 \%$ & $19,5 \%$ & $4,0 \%$ & $14,4 \%$ & $4,7 \%$ & $3,4 \%$ \\
\hline
\end{tabular}

${ }^{1}$ Total de casos que pueden localizarse a nivel de provincia.

TABla 8. Las diez provincias de España en las que más se localizaban los diferentes tipos de paisajes evocados por los alumnos.

Si se atiende a la tipología de los paisajes evocados en cada provincia, se aprecia que los alumnos evocaron fundamentalmente paisajes naturales próximos, es decir, que se encontraban en su provincia (61,2\% casos para Navarra) o en las geográficamente próximas (64,7\% para Zaragoza y $81,3 \%$ para Huesca). En esta misma línea, los paisajes 
costeros evocados predominaban frente a los naturales en Guipúzcoa (87,5\%), Tarragona $(81,8 \%)$, Castellón $(91,7 \%)$ y Alicante $(66,7 \%)$, hecho que parece apuntar a que los alumnos evocaron paisajes relacionados con sus destinos vacacionales ${ }^{5}$.

\subsubsection{Pregunta 3}

En la Tabla 9 se puede observar que el $73 \%$ de los encuestados consideraba que los elementos culturales (castillos, monumentos...) son parte del paisaje, seguido, aunque a distancia, por las grandes obras humanas (carreteras, embalses... 41,6\%) y los edificios $(39,5 \%)$. En el extremo opuesto se encuentra la opción de respuesta "elementos contaminantes", que obtuvo un $17,4 \%$. Debido a la limitación de espacio no se han mostrado los resultados desglosados por zonas, pero en ambas se aprecia el mismo patrón de respuesta.

\begin{tabular}{lccc}
\hline & \multicolumn{3}{c}{ Zona rural+ urbana } \\
\cline { 2 - 4 } \multicolumn{1}{c}{ Opciones de respuesta } & $\mathrm{n}^{\mathrm{o}}$ & $\%$ & $\begin{array}{c}\% \text { respuestas } \\
\text { respecto pre- } \\
\end{array}$ \\
& respuestas & respuestas & $\begin{array}{c}\text { guntas correc- } \\
\text { tas }(777)^{1}\end{array}$ \\
\hline Elementos culturales & 567 & $30,5 \%$ & $73,0 \%$ \\
Grandes obras humanas & 323 & $17,4 \%$ & $41,6 \%$ \\
Edificios & 307 & $16,5 \%$ & $39,5 \%$ \\
Elementos tecnológicos & 206 & $11,1 \%$ & $26,5 \%$ \\
Medios de transporte & 169 & $9,1 \%$ & $21,9 \%$ \\
Elementos contaminantes & 135 & $7,3 \%$ & $17,4 \%$ \\
\hline "Otros": elementos naturales: & 124 & $6,7 \%$ & $16,0 \%$ \\
$\quad$ - NO marca otras respuestas & 51 & $2,7 \%$ & $6,6 \%$ \\
$\quad$ - marca otras respuestas & 73 & $3,9 \%$ & $9,4 \%$ \\
\hline "Otros": ninguno de estos elementos & 9 & $0,5 \%$ & $1,3 \%$ \\
Otras respuestas categoría "Otros" & 16 & $0,9 \%$ & $2,1 \%$ \\
\hline Total & 1856 & $100,0 \%$ & $239,1 \%{ }^{2}$ \\
\hline${ }^{1}$ Preguntas válidas y que no se encuentran en blanco. & & \\
${ }^{2}$ Valores superiores al 100\% debido a que se pueden marcar varias opciones de res- \\
puesta en cada pregunta.
\end{tabular}

TABLA 9. Respuestas de la pregunta 3.

5 Los destinos vacacionales frecuentes de la población navarra suelen ser las zonas costeras (Instituto de Turismo de España, 2012). 
En cuanto a las respuestas que aportaron los alumnos en la categoría abierta "otros", el 16\% (124 casos) de ellos mostró que echaba en falta los elementos naturales en esta pregunta. Como se puede observar en la tabla, en color gris, de esos 124 casos, en $51(6,6 \%)$ los elementos naturales eran la única respuesta que se daba a la pregunta. En esta línea, el 1,3\% de los encuestados señaló específicamente que ninguno de los elementos reflejados en las respuestas formaba parte del paisaje. Por tanto, podría decirse que un 7,9\% de los encuestados no consideraba que los elementos humanos formaran parte del paisaje. Estos datos podrían apuntar a una concepción del paisaje en la que el ser humano no tiene cabida. Esta idea también estaría relacionada con el hecho de que en un gran porcentaje de los paisajes evocados predominaban los elementos naturales (apartado 3.2.1).

\section{PROPUESTAS DE MEJORA DE LA ENCUESTA}

Pese a que la encuesta permitió obtener información de gran utilidad para el diseño de propuestas didácticas adaptadas a las ideas previas de los alumnos, se detectaron algunos aspectos susceptibles de mejora, que se recogen a continuación.

\subsection{Aspectos de cumplimentado}

\subsubsection{Preguntas no válidas (1,5\%) y multiplicidad de respuestas (7\%)}

Dado que en las preguntas 1, 2 y 3 casi el $90 \%$ de los casos en que se consideraban no válidas era debido a la multiplicidad (apartado 3.1.4.), se prevé que solventando este problema se conseguirá minimizar también el primero. En este sentido, para evitar que los alumnos respondan a las preguntas 1 y 2 con más de un paisaje evocado se ha indicado en el texto de la pregunta 1 que, si han pensado en varios paisajes, elijan solo uno para responder a esas dos preguntas. En cuanto a la pregunta 3, se ha resaltado el texto que indicaba que a partir de ese momento había que responder a las encuestas en base a lo que sabían y no sobre su paisaje evocado.

Por último, para intentar lograr que los alumnos respondan correctamente sobre qué han aprendido sobre paisaje en el ámbito familiar y/o de las amistades (pregunta 6), se propone especificar más la pregunta y destacar tipográficamente la palabra "qué".

\subsubsection{Preguntas en blanco $(2,4 \%)$}

Para tratar de evitar las preguntas en blanco, se propone hacer hincapié, durante la explicación inicial a los alumnos, en la idea de que no pueden quedar preguntas sin responder, sugiriéndoles que, si las opciones de respuesta ofrecidas no se ajustan 
a sus necesidades, pueden añadir o completar la información utilizando el apartado "otros". También se incluirá esta idea en la sección dedicada a las explicaciones de cumplimentado.

En cuanto a la pregunta $1 \mathrm{c}$, sobre fauna $(10,7 \%$ de casos en la zona rural y $6 \%$ en la urbana), se ha considerado oportuno incluir una respuesta abierta "otros", de modo que los alumnos pueden indicar ahí si su paisaje tiene fauna o no.

\subsubsection{Cumplimentado incompleto de las preguntas (5\%)}

En relación con el cumplimentado de la localidad de residencia del alumno, visto lo sucedido con la Zona rural 2 -donde la mayoría de alumnos respondió con la localidad del instituto (apartado 3.1.3.)-, se ha especificado en la encuesta que se indique la "localidad de residencia".

Por último, otra forma de motivar al alumnado para que cumplimente adecuadamente la encuesta, sería realizarla en soporte digital mediante el empleo de herramientas online (Google Drive, Surveymonkey...). Este tipo de plataformas, además, permiten limitar el avance en las preguntas, de modo que el alumno no pueda pasar a la siguiente hasta no haber respondido a la anterior. De este modo se evitarían también las preguntas en blanco. No obstante, la opción de realizar los cuestionarios online depende de la dotación tecnológica de cada centro educativo.

\section{2. Ítems de la encuesta: pregunta 1}

En la pregunta 1a se ha decidido separar las opciones de respuesta de relieve (1a) y de hidrología (1b), lo que ha permitido dividir en dos las respuestas "valle/barranco" y "río/lago", así como incluir la opción de respuesta "mar", dada la importante presencia del paisaje costero (14,6\%, apartado 3.2.1.).

Respecto a la pregunta $1 \mathrm{~b}$, sobre vegetación, se ha cambiado la opción de respuesta "jardín" por "prado", ya que los resultados parecen apuntar a que los alumnos confundían el primero con el segundo. Paralelamente, se ha eliminado la opción "campo sin cultivar", ya que, a veces, en el contexto en el que aparecía, no quedaba claro si el paisaje evocado era de tipo rural y, ante la duda, se incluía en la tipología "otros".

En relación con la pregunta 1c, se ha decidido eliminar la opción de respuesta "mascotas", ya que, como ha señalado anteriormente, cuando solo aparecía ésta marcada, dificultaba notablemente la clasificación de los paisajes evocados.

Por último, se ha incorporado una sección más a esta pregunta, de respuesta abierta, para que los alumnos puedan incorporar de forma más sencilla información sobre los posibles elementos antrópicos de sus paisajes evocados. 


\subsection{Nueva versión de la encuesta}

Todas las modificaciones descritas en los apartados anteriores se han incorporado en una nueva versión de la encuesta, que se muestra a continuación (Figura 5).

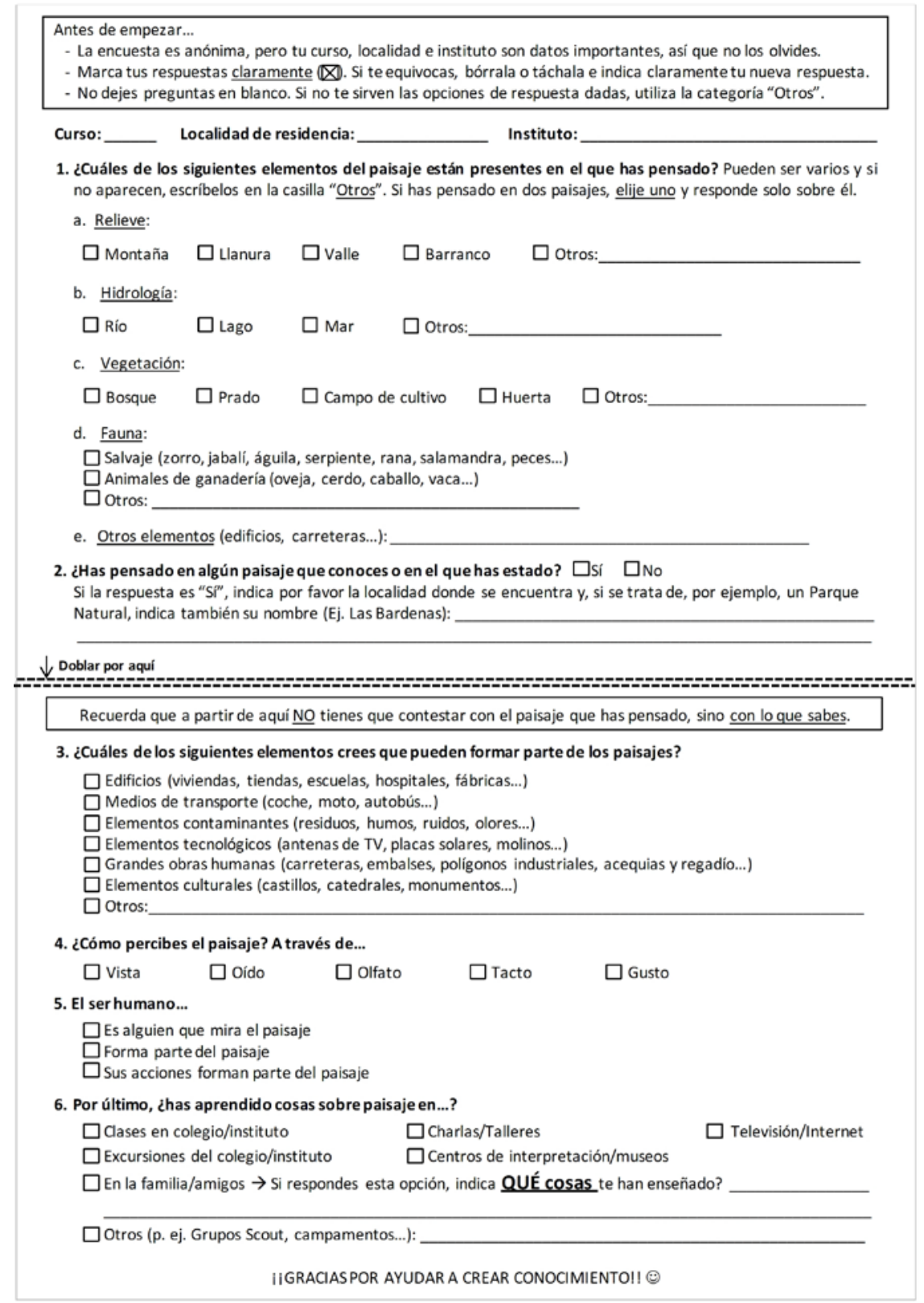

FiguRA 5. Nueva versión de la encuesta. Fuente: elaboración propia. 


\section{APLICACIÓN DOCENTE DE LA ENCUESTA}

En el curso 2015-2016, tras haber analizado las encuestas de la Zona urbana 1 y las zonas rurales 2 y 3 (ver apartado 2.3.), se diseñaron y aplicaron dos propuestas didácticas, que se presentan brevemente a continuación.

La primera de ella es “„Descubriendo el paisaje!”, un taller de una hora de duración destinado al alumnado de $5^{\circ}$ y $6^{\circ}$ de Educación Primaria y $1^{\circ}$ de $\mathrm{ESO}^{6}$. En este taller se aborda el estudio de los elementos naturales y humanos del paisaje, haciendo hincapié en que el ser humano no es un elemento externo a él, sino que forma parte del mismo y, en consecuencia, lo modifica. La actividad se plantea como un juego en el que alumnos tienen que construir un puzle, cuyas fichas son los distintos elementos del paisaje. Los alumnos, divididos en dos equipos, tienen que conseguir dichas fichas respondiendo adecuadamente a varias preguntas. Uno de los equipos trabaja con los paisajes del norte de Navarra y el otro con los del sur, ya que, debido a sus fuertes contrastes, ilustran muy bien cómo los diferentes elementos del paisaje influyen en su configuración (Casas, Erneta y Puig, 2017) ${ }^{7}$. Este taller se puso en práctica en cuatro centros docentes de Navarra (440 alumnos) y en Sendaviva (24 sujetos) (Casas, Puig y Erneta, 2017b), un parque de la naturaleza situado al sur de la Comunidad Foral, con vistas al emblemático paisaje tabular de Las Bardenas Reales.

La segunda propuesta didáctica es "Mismos paisajes, nuevas miradas", que, diferencia de la anterior, implica el empleo de las Tecnologías de la Información y la Comunicación en el aula (Casas y Erneta, 2017). Está diseñada para un nivel de $3^{\circ}$ de ESO y contempla 5 sesiones ordinarias del horario lectivo. En ella se aborda el concepto de paisaje -incluyendo los aspectos subjetivos asociados al observador-, los elementos que lo constituyen, una clasificación de tipos de paisajes, sentidos implicados en la percepción y, al igual que en la propuesta didáctica anterior, el papel de ser humano en el paisaje: observador, constitutivo y modelador. Esta propuesta se llevó a cabo en un instituto de Navarra y en ella participaron 22 alumnos (Casas y Erneta, 2016).

Ambas propuestas didácticas se desarrollaron en un contexto de investigación, en el cual se buscaba identificar si se producían cambios en las ideas previas del alumnado

\footnotetext{
${ }^{6}$ Se decidió incluir el último ciclo de Educación Primaria porque al analizar las encuestas se observó que los resultados no diferían mucho entre los cuatro cursos de la ESO, de modo que era posible que las ideas estereotipadas sobre paisaje estuvieran presentes ya en la etapa educativa previa.

7 El artículo contiene una descripción detallada de la propuesta didáctica. Por otra parte, los materiales didácticos diseñados pueden descargarse en el siguiente enlace: http://hdl.handle. net/10171/43099.
} 
tras participar en las propuestas didácticas. Para ello se aplicó una metodología pretestpostest, empleando unas encuestas que, si bien se diseñaron específicamente para cada caso, se basaron en gran medida en la que aquí se ha presentado.

\section{CONCLUSIONES}

Las principales conclusiones de este estudio se enumeran a continuación:

1. La encuesta se muestra útil como herramienta para obtener información sobre las ideas previas del alumnado de ESO de Navarra, residente tanto en zonas rurales como en zonas urbanas.

El cuestionario dirigido que contempla también la posibilidad de añadir información no prefijada (categoría de respuesta "otros"), se muestra, frente a otras alternativas -como por ejemplo un cuestionario totalmente abierto-, como la más adecuada para este grupo poblacional, ya que, como se ha podido comprobar, en las preguntas 2 y 6 , en las que los alumnos debían aportar información, se han dado un $5 \%$ de casos de respuestas incompletas.

Paralelamente, el hecho de que las preguntas sean independientes, a excepción de la 1 y la 2 , hace que no se invaliden encuestas completas, obteniendo así un elevado porcentaje de respuestas válidas $(98,4 \%)$.

Por otra parte, el análisis de aspectos de cumplimentado revela un bajo porcentaje de preguntas en blanco $(2,4 \%)$-que se debe en gran medida a la pregunta $1 \mathrm{c}-\mathrm{y}$ algunos casos de multiplicidad de respuestas (7\%) para las preguntas 1, 2, 3 у 6 . Previsiblemente, estos problemas se solventarán en gran medida con la nueva versión de la encuesta.

Por último, en relación con los aspectos de cumplimentado, los resultados muestran que no se aprecian diferencias importantes entre las zonas rurales y las urbanas.

2. La elección de los ítems del cuestionario resulta, en general, adecuada, aunque mejorable, tal y como se recoge en la nueva versión de la encuesta.

En relación con la pregunta 1, tal y como se preveía, el 71,5\% de los alumnos evocaron paisajes en los que predominaban los elementos naturales, de modo que la elección de ítems resultó adecuada. Además, la opción de respuesta "otros" permitió al 28,5\% restante de los sujetos encuestados describir sus paisajes evocados, que no eran predominantemente naturales. No obstante, a un 9,7\% del total de los paisajes evocados no se le pudo asignar posteriormente una tipología específica (paisaje natural, rural, costero...), de modo que se incorporaron a la categoría de otros paisajes. Este hecho ha llevado a modificar algunas opciones de respuesta.

En cuanto a la pregunta 3, el 17,3\% de los alumnos reivindicó a través de la 
opción de respuesta "otros" que, o bien los paisajes pueden estar constituidos por elementos naturales (16\%) o que ninguna de las opciones de respuesta prefijadas (elementos humanos) hacían referencia a elementos del paisaje $(1,3 \%)$. Por tanto, se considera que los ítems elegidos para esta pregunta son adecuados.

3. Los tres tipos de paisaje más evocados por los alumnos fueron el natural $(49,2 \%)$, el rural $(20,9 \%)$ y el costero $(14,5 \%)$ y, en general, representaban lugares que conocían o habían visitado $(56,1 \%)$. La mayoría de estos paisajes se localizaban en España $(86,6 \%)$, fundamentalmente en la Comunidad Foral de Navarra $(55,7 \%)$ y sus provincias limítrofes (Guipúzcoa, Huesca y Aragón), así como en algunas provincias de las costas cantábrica (Asturias y Cantabria) y mediterránea (Tarragona, Castellón y Alicante).

4. Algunos sujetos encuestados (7,9\%) señalaron en la pregunta 3, sobre los elementos humanos del paisaje, que solo los elementos naturales formaban parte de éste, hecho que podría apuntar a una posible idea estereotipada de paisaje, que reduce esta realidad a sus componentes naturales.

\section{AGRADECIMIENTOS}

A la Fundación Tatiana Pérez de Guzmán el Bueno, por su apoyo para realizar esta investigación.

\section{BIBLIOGRAFÍA}

Adrados, M. T., 1998. "Ideas previas y concepto de paisaje en alumnos de Primaria" en J. R. De Vera, E. M. Tonda, y M. J. Marrón, eds. IV Jornadas de Didáctica de la Geografía. Educación y Geografía. Alicante: Asociación de Geógrafos Españoles, pp. 145-151. [En línea] Disponible en <http://www.age-geografia.es/ didacticageografia/docs/Publicaciones/Educacion_Geografia_final.pdf> [Último acceso 20 junio 2018]

Álvarez, M. F., y Rubio, F., 1996. “Conocimiento del medio y los paisajes humanizados” en Universidad Complutense de Madrid y Asociación de Geógrafos Españoles, eds. III Jornadas de Didáctica de la Geografía. Madrid: Universidad Complutense de Madrid, pp.219-226.[Enlínea]Disponibleen<http://www.age-geografia.es/didacticageografia/ docs/Publicaciones/III\%20Jornadas.pdf> [Último acceso 20 junio 2018]

Barbadillo, F., 2016. Manual para observar e interpretar paisajes. Castellón: Tundra.

Benayas, J., 1992. Paisaje y educación ambiental, evaluación de cambios de actitudes hacia el entorno. Madrid: Ministerio de Obras Públicas y Transportes. Centro de publicaciones. 
Bernáldez, F. G., Gallado, D., y Abello, R. F., 1987. “Children’s landscape preferences: From rejection to attraction". Journal of Environmental Psychology, 7(2), pp. 169-176.

Bisquerra, R., 2014. Metodología de la investigación educativa. $4^{\mathrm{a}}$ ed. Barcelona: La Muralla.

Bovet, M. T., Pena, R., y Ribas, J., 2004. "El paisaje como recurso educativo en el marco de la educación para la participación”. Didáctica Geográfica, 6, pp. 3348. [En línea] Disponible en <http://www.didacticageografica.es/index.php/ didacticageografica/article/view/178/169> [Último acceso 20 junio 2018]

Busquets, J., 2002. "El paisatge: patrimoni en mutació i recurs didàctic formatiu en l'àmbit europeu". Temps D'e Educació, 26, pp. 45-52. [En línea] Disponible en <http://www.raco.cat/index.php/TempsEducacio/article/view/126333/177365> [Último acceso 20 junio 2018]

Busquets, J., 2011. "La importància de l'educació en paisatge" en J. Nogué, L. Puigbert, G. Bretcha, y À. Losantos, eds. Paisatge i Educació. Plecs de Paisatge: reflexions 2. Olot: Observatori del Paisatge de Catalunya,pp. 69-88. [En línea] Disponible en $<$ http://www.catpaisatge.net/fitxers/publicacions/paisatge_educacio/paisatge_i_ educacio.pdf> [Último acceso 20 junio 2018]

Casas, M., y Erneta, L., 2016. "Mismos paisajes, nuevas miradas: Experiencia de Flipped Classroom con alumando de $3^{\circ}$ de ESO” en L. Alanís, J. Almuedo, G. De Oliveira, R. Iglesias, y B. Pedregal, eds. XI Congreso Nacional Didáctica de la Geografía. Nativos digitales y geografía en el siglo XXI: educación geográfica y sistemas de aprendizaje. Sevilla: Asociación de Geógrafos Españoles-Universidad Pablo Olavide-Universidad de Alicante, pp. 155-172. [En línea] Disponible en <http:// www.age-geografia.es/didacticageografia/docs/Publicaciones/2016_nativos_ digitales_y_geografia.pdf> [Último acceso 20 junio 2018]

Casas, M., y Erneta, L., 2017. "Propuesta didáctica para la enseñanza del paisaje a través del empleo de la metodología Flipped Classroom”. Publicaciones Didácticas, 78, pp. 448-464. [En línea] Disponible en <https://publicacionesdidacticas.com/ hemeroteca/pd_078_ene.pdf> [Último acceso 20 junio 2018]

Casas, M., Erneta, L., y Puig, J., 2017. “¡Descubriendo el paisaje!: propuesta didáctica para 3er ciclo de Primaria y $1^{\circ}$ de ESO”. Publicaciones Didácticas, 82, pp. 562582. [En línea] Disponible en <https://publicacionesdidacticas.com/hemeroteca/ articulo/082078/articulo-pdf> [Último acceso 20 junio 2018]

Casas, M., Puig, J., y Erneta, L., 2017a. "El paisaje en el contexto curricular de la LOMCE: una oportunidad educativa, ¿aprovechada o desaprovechada?”. 
Didáctica Geográfica, 18, pp. 39-68. [En línea] Disponible en <http://www. age-geografia.es/didacticageografica/index.php/didacticageografica/article/ view/393/366> [Último acceso 20 junio 2018]

Casas, M., Puig, J., y Erneta, L., 2017b. "El paisaje como recurso para la Educación Ambiental. Experiencia práctica en el Equipamiento "Sendaviva" (Navarra)". Observatorio Medioambiental, 20, pp. 111-136. [En línea] Disponible en <https:// revistas.ucm.es/index.php/OBMD/article/view/57949/52143> [Último acceso 20 junio 2018]

Castiglioni, B., 2011. "L'educació en paisatge des de l'òptica del Conveni europeu del paisatge i noves perspectives" en J. Nogué, L. Puigbert, G. Bretcha, y À. Losantos, eds. Paisatge i Educació. Plecs de Paisatge: reflexions 2. Olot: Observatori del Paisatge de Catalunya, pp. 153-167. [En línea] Disponible en: <http://www. catpaisatge.net/fitxers/publicacions/paisatge_educacio/paisatge_i_educacio.pdf> [Último acceso 20 junio 2018]

Cohen, L., Manion, L., y Morrison, K., 2011. Research Methods in Education. $6^{\text {a }}$ ed. Londres: Routledge Falmer.

Consejo de Europa, 2000. Convenio Europeo del Paisaje. Florencia. [En línea. Acceso libre] Disponible en <http://www.mecd.gob.es/cultura-mecd/dms/mecd/culturamecd/areas-cultura/patrimonio/Convenio_europeo_paisaje.pdf> [Último acceso 20 junio 2018]

Consejo de Europa, 2009. 5th Council of Europe Conference on the European Landscape Convention. Education on Landscape for Children. [En línea. Acceso libre] Disponible en <https://rm.coe.int/16806b081b> [Último acceso 20 junio 2018]

Crespo, J. M., 2012. "Un itinerario didáctico para la interpretación de los elementos físicos de los paisajes de la Sierra de Guadarrama”. Didáctica Geográfica, 13, pp. 15-34. [En línea] Disponible en <http://www.didacticageografica.es/index.php/ didacticageografica/article/viewFile/94/94> [Último acceso 20 junio 2018]

García, A. B., y Benavides, M., 1996. "El paisaje a través de los ojos de un niño" en Universidad Complutense de Madrid y Asociación de Geógrafos Españoles, eds. III Jornadas de Didáctica de la Geografía. Madrid: Universidad Complutense de Madrid, pp. 265-276. [En línea] Disponible en <http://www.age-geografia.es/ didacticageografia/docs/Publicaciones/III\%20Jornadas.pdf> [Último acceso 20 junio 2018]

García de la Vega, A., 2011. "El paisaje: un desafío curricular y didáctico". Didácticas Específicas, 4, pp. 1-19. [En línea] Disponible en <https://repositorio.uam.es/ handle/10486/7438> [Último acceso 20 junio 2018] 
Instituto de Turismo de España, 2012. Informe anual 2012. Movimientos turísticos de los españoles (FAMILITUR). Madrid. [En línea. Acceso libre] Disponible en $<$ http://www.iet.tourspain.es/es-ES/estadisticas/familitur/Anuales/Informe anual de Familitur. Año 2012.pdf> [Último acceso 20 junio 2018]

Liceras, A., 2003. Observar e interpretar el paisaje. Estrategias didácticas. Granada: Grupo Editorial Universitario.

López, F., 1995. "La Adolescencia" en Guía de Salud y Desarrollo Personal para trabajar con Adolescentes. Navarra: Instituto de Salud Pública de Navarra. Gobierno de Navarra, pp. 16-18.

Sanz, C., y López, N., 1996. "El paisaje en su dimensión educativa" en Universidad Complutense de Madrid y Asociación de Geógrafos Españoles, eds. III Jornadas de Didáctica de la Geografía. Madrid: Universidad Complutense de Madrid, pp. 363370. [En línea] Disponible en <http://www.age-geografia.es/didacticageografia/ docs/Publicaciones/III\%20Jornadas.pdf> [Último acceso 20 junio 2018]

Souto, X. M., 1996. "Metodología y procedimientos en Didáctica de Geografía: La propuesta del Proyecto GEA" en Universidad Complutense de Madrid y Asociación de Geógrafos Españoles, eds. III Jornadas de Didáctica de la Geografía. Madrid: Universidad Complutense de Madrid, pp. 173-184. [En línea] Disponible en $<$ http://www.age-geografia.es/didacticageografia/docs/Publicaciones/III\%20 Jornadas.pdf> [Último acceso 20 junio 2018]

Tonda, M.E., y Sebastiá, R., 2000. "El paisaje y las ideas previas en alumnos de Primaria" en J. L. González y M. J. Marrón, eds. Geografía, profesorado y sociedad. Teoría y práctica de la Geografía en la enseñanza. Murcia: Asociación de Geógrafos Españoles-Universidad de Murcia, pp. 397-409. [En línea] Disponible en <http:// www.age-geografia.es/didacticageografia/index.php?m=4> [Último acceso 20 junio 2018] 